\title{
Neighbourhood maternal socioeconomic status indicators and risk of congenital heart disease
}

\author{
Qun Miao ${ }^{1,2,3^{*}}$, Sandra Dunn ${ }^{1,2,4,5}$, Shi Wu Wen ${ }^{3,4,6}$, Jane Lougheed ${ }^{2,7,8}$, Jessica Reszel ${ }^{1,2}$,
} Carolina Lavin Venegas ${ }^{1,2}$ and Mark Walker ${ }^{1,2,3,4,6}$

\begin{abstract}
Background: This study aimed to examine the relationships between various maternal socioeconomic status (SES) indicators and the risk of congenital heart disease (CHD).

Methods: This was a population-based retrospective cohort study, including all singleton stillbirths and live births in Ontario hospitals from April 1, 2012 to March 31, 2018. Multivariable logistic regression models were performed to examine the relationships between maternal neighbourhood household income, poverty, education level, employment and unemployment status, immigration and minority status, and population density and the risk of CHD. All SES variables were estimated at a dissemination area level and categorized into quintiles. Adjustments were made for maternal age at birth, assisted reproductive technology, obesity, pre-existing maternal health conditions, substance use during pregnancy, rural or urban residence, and infant's sex.
\end{abstract}

Results: Of 804,292 singletons, 9731 (1.21\%) infants with CHD were identified. Compared to infants whose mothers lived in the highest income neighbourhoods, infants whose mothers lived in the lowest income neighbourhoods had higher likelihood of developing CHD (adjusted OR: 1.29, 95\% Cl: 1.20-1.38). Compared to infants whose mothers lived in the neighbourhoods with the highest percentage of people with a university or higher degree, infants whose mothers lived in the neighbourhoods with the lowest percentage of people with university or higher degree had higher chance of CHD (adjusted OR: 1.34, 95\% Cl: 1.24-1.44). Compared to infants whose mothers lived in the neighbourhoods with the highest employment rate, the odds of infants whose mothers resided in areas with the lowest employment having CHD was 18\% higher (adjusted OR: 1.18, 95\% Cl: 1.10-1.26). Compared to infants whose mothers lived in the neighbourhoods with the lowest proportion of immigrants or minorities, infants whose mothers resided in areas with the highest proportions of immigrants or minorities had 18\% lower odds (adjusted OR: 0.82 , 95\% Cl: 0.77-0.88) and 16\% lower odds (adjusted OR: 0.84, 95\% Cl: 0.78-0.91) of CHD, respectively.

(Continued on next page)

\footnotetext{
* Correspondence: GMiao@bornontario.ca

'BORN Ontario, Ottawa, Ontario, Canada

${ }^{2}$ Children's Hospital of Eastern Ontario Research Institute, Ottawa, Ontario,

Canada

Full list of author information is available at the end of the article
}

(c) The Author(s). 2021 Open Access This article is licensed under a Creative Commons Attribution 4.0 International License, which permits use, sharing, adaptation, distribution and reproduction in any medium or format, as long as you give appropriate credit to the original author(s) and the source, provide a link to the Creative Commons licence, and indicate if changes were made. The images or other third party material in this article are included in the article's Creative Commons licence, unless indicated otherwise in a credit line to the material. If material is not included in the article's Creative Commons licence and your intended use is not permitted by statutory regulation or exceeds the permitted use, you will need to obtain permission directly from the copyright holder. To view a copy of this licence, visit http://creativecommons.org/licenses/by/4.0/ The Creative Commons Public Domain Dedication waiver (http://creativecommons.org/publicdomain/zero/1.0/) applies to the data made available in this article, unless otherwise stated in a credit line to the data. 
(Continued from previous page)

Conclusion: Lower maternal neighbourhood household income, poverty, lower educational level and unemployment status had positive associations with CHD, highlighting a significant social inequity in Ontario. The findings of lower CHD risk in immigrant and minority neighbourhoods require further investigation.

Keywords: The Better Outcomes Registry \& Network (BORN) database, The Canadian Institute for Health Information Discharge Abstract Database (CIHI-DAD), Congenital heart disease, Socioeconomic status, Immigrants, Minorities

\section{Background}

Congenital heart disease (CHD) is a leading cause of infant morbidity and mortality in Canada and worldwide $[1,2]$. The prevalence rate is estimated at 3.7 to 17.5 cases per 1000 live births, comprising 30 to $45 \%$ of all congenital anomalies (CAs) globally [1, 3-7]. In Canada, the overall CHD prevalence rate has been estimated at 12.3 per 1000 total births $[8,9]$. In North America, it has been reported that $37 \%$ of deaths in infants with CAs are secondary to $\mathrm{CHD}[1,3,10]$.

The etiology of CHD remains unclear [3], although previous studies have reported that certain risk factors may contribute to the development of $\mathrm{CHD}$, which include genetic factors and environmental factors such as advanced maternal age, rubella virus infection, exposure to environmental hazards during pregnancy, pre-pregnancy maternal obesity, the use of assisted reproductive technology (ART), certain medications, maternal social drug use, smoking, alcohol consumption during pregnancy, maternal pre-existing diabetes, and gestational diabetes [11-13].

Another potential risk factor for CHD is maternal socioeconomic status (SES) disparities [11, 12], although published findings regarding socioeconomic disparities and the risk of CHD are inconsistent. A recent meta-analysis combining data from 31 casecontrol studies and two cohort studies found that compared to reference groups, the risk of CHD was $11 \%$ higher for lower levels of maternal education (pooled $\mathrm{RR}=1.11,95 \% \mathrm{CI}: 1.03,1.21), 5 \%$ higher for lower family income (pooled $\mathrm{RR}=1.05,95 \% \mathrm{CI}: 1.01,1.09$ ), and $51 \%$ higher for maternal exposure to certain occupations (pooled $\mathrm{RR}=1.51,95 \% \mathrm{CI}: 1.02,2.24$ ) [12]. However, the results were not consistent by all geographic areas and various SES indicators [12]. Conversely, another recent meta-analysis of two ecological, seven case-control and two cohort studies did not find associations between neighbourhood SES variables and the risk of CHD [13]. Moreover, a recent populationbased study in Ontario, Canada found that children born in lower SES neighbourhoods (23\% of all births) had $20 \%$ higher risk of CHD (RR: 1.20 ; 95\% CI: $1.15-$ 1.24) [14]. This finding is consistent with the results that we observed when we examined an association between ART and CHD in another study [15]. However, some studies had methodological limitations. For example, one meta-analysis that showed positive findings mainly relied on case-control studies with small sample sizes and may have been prone to information and selection bias [16]. Furthermore, a few studies conducted in Canada did not control for important confounders in their multivariable regression analyses [14, 17].

An explanation for this relationship between SES and risk of CHD remains unknown [12]. A lower SES level may be a proxy of environmental and behavioral factors such as smoking, social drug use, alcohol consumption, poor nutritional dietary habits, disadvantaged environmental living conditions, adverse maternal health conditions such as diabetes or uncontrolled residual confounding [12, 18, 19]. In addition, mothers with a lower SES level often experience poverty, which could lead to psychological stress, potentially elevating the production of corticosteroids, altering the immune system in pregnant women, and then possibly increasing the risk of having an infant with CHD [20, 21].

In Canada, social inequity has worsened, and income and wealth disparities have grown wider in the past two decades [22, 23]. According to 2016 Census data, 4.8 million Canadians are living in poverty and 1.2 million (20\%) children live in low-income households [24]. It has been estimated that in Canada each year at least 50,000 children are born into poverty and 1 of 80-100 infants are born with CHD in Canada [4, 25]. Considering Ontario consists of $39 \%$ of Canada's population, social inequity would be a major concern in prenatal health if pregnant women with a lower SES have an increased risk of CHD [26].

Moreover, SES has multiple dimensions; no single indicator can encompass all perspectives [27]. In the past, household income and education level were the two main SES factors studied [12]. There is limited research measuring other factors. In this study, we aimed to use multiple community SES factors to examine the relationships between SES and the risk of CHD from different angles.

\section{Methods}

Study design: We conducted a population-based retrospective cohort study with Ontario data from April 1st 2012 to March 31st 2018. 


\section{Study population}

The study included all late stage terminations (pregnancies terminated at gestational age $\geq 20$ weeks or birthweight $\geq 500 \mathrm{~g}$ ) and births (live births and stillbirths) in Ontario hospitals from April 1st 2012 to March 31st 2018 , with a birth weight $\geq 500 \mathrm{~g}$, or gestational age $\geq 20$ weeks. Records of mothers or infants residing outside of Ontario were excluded.

\section{Data sources}

The Better Outcomes Registry \& Network Ontario (BORN) is a registry that collects data on every pregnancy and birth in Ontario through the BORN Information System (BIS). The BORN prenatal databases capture data on maternal demographic characteristics and health behaviors, pre-existing maternal health problems, prenatal screening, obstetric complications, intra-partum interventions, fetal anomalies and outcomes in pregnancy, labour and birth, and postpartum stages [28]. The data are collected at various encounters but they are also aggregated into maternal pregnancy and infant datasets. Datasets in the BIS were used to perform the analysis including aggregate pregnancy, aggregate infant, antenatal specialty for high risk pregnant individuals, prenatal screening, and prenatal screening follow-up data. BORN strives to ensure high data quality in the BIS through an ongoing data validation process, quality checks, and formal training sessions for individuals entering data [28]. A number of papers and reports have been published using these data [28-31].

We also used the Discharge Abstract Database (DAD) and the National Ambulatory Care Reporting System (NACRS), which are run and maintained by the Canadian Institute for Health Information (CIHI) [32]. Each year, BORN receives CIHI-DAD and CIHI-NACRS data including maternal, newborn, and child (up to 1 year of age) records from acute care and emergency facilities in Ontario [33]. By using these data sources in conjunction with the BIS data, we are able to identify infants who had a diagnosis of CHD in hospital up to 1 year of age.

The 2016 Canadian Census and Postal Code Conversion File Plus $(\mathrm{PCCF}+)$ version $7 \mathrm{~B}$ were employed for all neighbourhood data [34]. The 2016 Canadian Census is the latest Canada-wide census performed by Statistics Canada [35]. These data include Canadian social demographic information including household income, education, ethnicity, immigration, employment, and types of dwelling by different levels of geography [35]. Statistics Canada and Canada Post also developed the PCCF+, which contains postal codes matched with different levels of geography in Census data. The PCCF+ version $7 \mathrm{~B}$ is the latest version reflecting the most up to date postal codes and their corresponding dissemination areas (DAs), which are small geographic areas, including 400-700 persons [34]. By linking these two files to the study cohort using maternal residence postal codes, we were able to obtain maternal neighbourhood level SES and minority and immigration status information at a dissemination area level.

\section{Data linkages}

The linkage process started within the BIS system. The baseline study cohort was obtained from the aggregate infant data of birthdates within the study timeframe. The outcome of CHD, SES variables (exposures) and covariates were obtained from multiple data sources (please see the data linkage flow chart in Fig. 1).

\section{Outcomes}

All CHD cases captured in the prenatal stage were identified from the antenatal speciality and prenatal screening follow-up datasets in the BIS. Newborn diagnoses for CHD were collected from the birth child, postpartum child and neonatal intensive care encounters in the BIS and were aggregated into one infant dataset. We captured the newborn CHD from the aggregate infant dataset. Additional newborn CHD and CHD diagnosed during the infant's first year were identified from the CIHI-DAD and CIHI-NACRS databases. In the BIS, CHD was coded in an anomaly picklist, which was based on clinical diagnosis. In the CIHI datasets, CHD was coded using the International Statistical Classification of Diseases and Related Health Problems, 10th Revision, Canadian adaptation (ICD-10-CA). Please see the CHD definitions of the BIS picklist values in the BIS data and the ICD-10-CA codes in the CIHI data in Appendix A.

\section{Covariates}

This derived baseline infant dataset was linked to the aggregate maternal pregnancy data in the BIS to obtain maternal information including maternal age at delivery, conception type, pre-pregnancy body mass index (BMI), pre-pregnancy weight and height, pre-existing conditions and health conditions during pregnancy (including physical and mental health status), social drug use, as well as alcohol consumption and smoking status during pregnancy.

\section{SES measurement}

SES, which reflects the social position or class of an individual, a family or a group of persons in a society, was linked to multiple social and economic factors [36]. There is no standard or universal SES measurement method in health equality research [36]. The most 


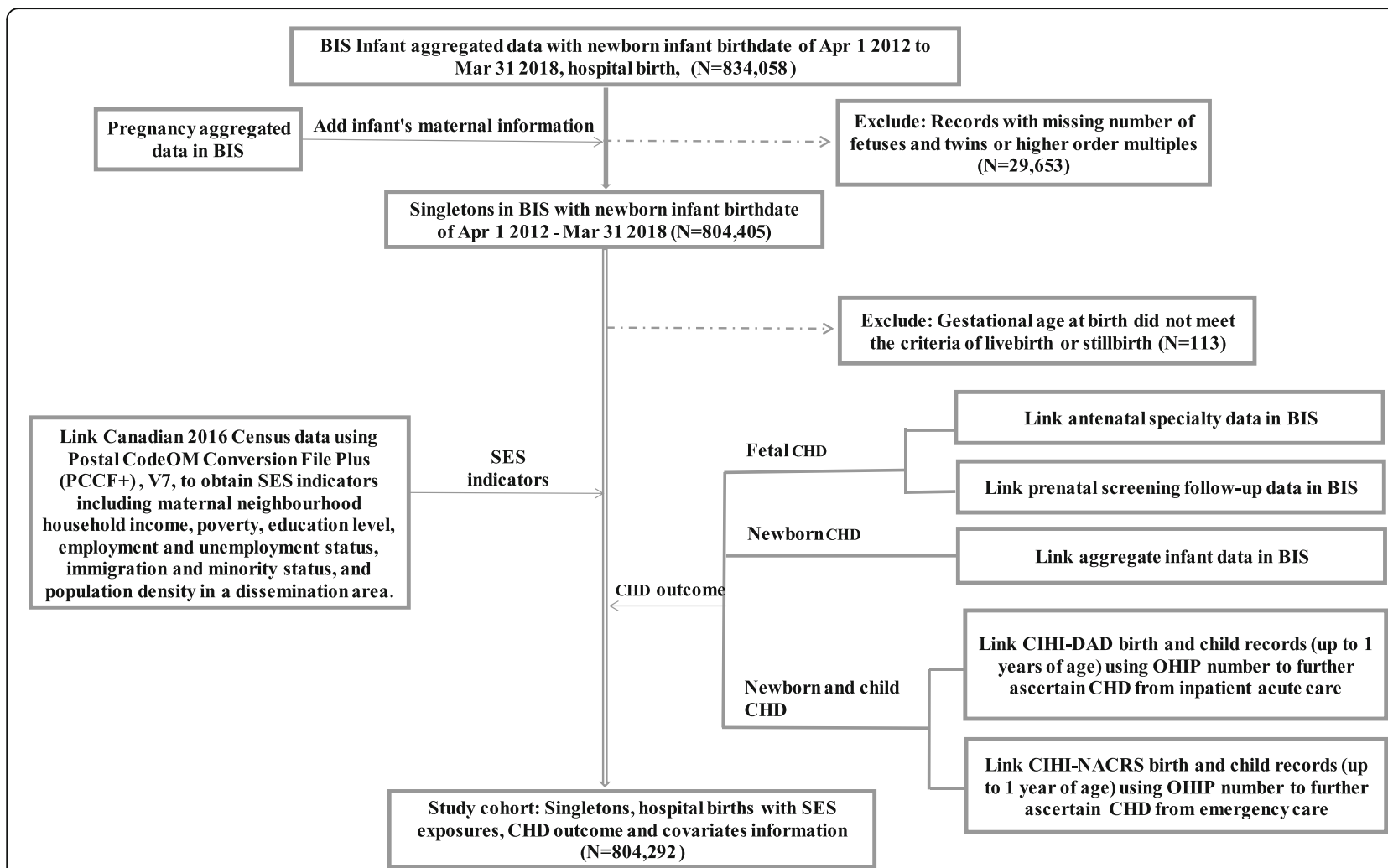

Fig. 1 Flowchart of data sources and data linkage for the study cohort. Abbrev: BIS: BORN Information System, SES: socioeconomic status, OHIP: Ontario Health Insurance Plan, V7: version 7

common indicators in the literature are household income and education [36]. Due to the multiple dimensions of SES, we included more indicators in this research. Based on the World Health Organization's (WHO) [37] social determinants of health framework and available SES information, we measured SES using the indicators described below.

For the income related SES indicators, we assessed neighbourhood median household income after tax and before tax adjusted by size of household. Poverty was assessed according to the percentage of children aged 0-17 years living in low income households, the percentage of children aged $0-5$ years living in low income households, and the percentage of all people with low income. Education level was assessed based on the percentage of adults aged 25-64 years having a university or higher degree and the percentage of adults aged 25-64 years without a high school diploma. We also assessed the percentage of minorities, the percentage of immigrants, the rate of unemployment among those aged 15 years or over, the rate of employment among those aged 15 years or over and population density. All SES and minority and immigration status indicators were assessed at a DA level in the province of Ontario and categorized as quintiles (Q1 = lowest, Q5 = highest) using the 2016 Canadian Census data.

\section{Statistical analysis}

We first described the distributions of exposure variables and covariates by CHD. Spearman's rank-order correlations for ordinal variables were assessed among all SES variables. The Cochran-Armitage trend test was performed to evaluate the exposure of "dose-response" relationships between quintiles of all SES variables and the risk of CHD. Multivariable logistic regression models were conducted to examine the relationships between the maternal neighbourhood household income, poverty, education level, employment and unemployment status, immigration and minority status, and population density and the risk of $\mathrm{CHD}$. Adjustments were made for maternal age at birth, ART, obesity, preexisting health conditions, substance use during pregnancy, rural or urban residence, and infant's sex. CHD is a rare outcome, therefore, odds ratios (ORs) and risk ratios are very close. Thus, we used odds ratios to estimate risk ratios.

Since most SES indicators were highly correlated, one SES variable was assessed in each separate multivariable regression model. All data linkages and analysis were performed using SAS 9.4 [38].

\section{Ethical considerations}

This study was approved by the Children's Hospital of Eastern Ontario Research Ethics Board and the Ottawa Health Science Network Research Ethics Board. 


\section{Results}

The study cohort consisted of 804,292 singletons born in hospital, including 3534 stillbirths $(0.44 \%$ of the study population) and 1599 terminations $(0.20 \%$ of the study population). In this cohort, 9731 (1.21\%) infants with any type of CHD were identified, of which 300 fetuses (3.08\% of 9731) were terminated and 125 fetuses (1.28\% of 9731) were spontaneous losses. Table 1 shows the distributions of maternal and infant demographic factors and maternal behavioral factors, medical history, and health conditions. The average maternal age (mean $\pm \mathrm{SD})$ at birth was $30.56 \pm 5.32$ years. There were more male infants $(412,809$, $51.38 \%$ of total births) than female infants. The mean gestational age (mean $\pm \mathrm{SD})$ at birth was $38.79 \pm 2.12$ weeks. In total, 93,402 singletons (11.7\%) lived in rural areas.

Table 2 shows the distributions of SES indicators categorized into quintiles on a DA level in Ontario. Compared to the distributions of median household income after tax adjusted by the size of household in the Ontario general population, there were more infants whose mothers lived in the poorest neighbourhoods (Q1, 24.01\%) and fewer infants living in the richest neighbourhoods (Q5, 15.17\%). The prevalence of CHD decreased from 1.33 (Q1) to 1.09 (Q5) accordingly, which was statistically significant based on the trend test $(p<0.0001)$. The prevalence and trend patterns were similar for other neighbourhood household income indicators, including median household income before tax adjusted by size of household, median household income after tax, and median household income before tax. For the variables of percentage of all people with low income and percentage of children aged 0-17 years with low income, the highest proportions of mothers (24.34 and $23.54 \%$, respectively) lived in the poorest neighbourhood (Q5) and their infants had the highest prevalence of CHD (1.34 and 1.33\%, respectively). For the variable children ages $0-5$ years with low income, the highest proportion of mothers lived in the Q3 neighbourhoods (23.41\%) and the highest CHD prevalence rate occurred in the Q5 neighbourhoods (1.40\%). All three low income variables showed an increase in the prevalence of CHD rates from Q1 to Q5 with a statistically significant trend test.

This cohort was almost equally distributed within quintiles on the education variable of percentage of people aged 25-64 years without a high school diploma, while the CHD prevalence rate increased from Q1 to Q5 and showed a statistically significant trend. On the other hand, for the variable people aged 2564 years who had a university degree or higher, the

Table 1 Maternal and infant characteristics of study population

\begin{tabular}{|c|c|}
\hline Variable* & $\begin{array}{l}\text { Total cohort } \\
(n=804,292)\end{array}$ \\
\hline Maternal pre-pregnancy body mass index (BMI) in $\mathrm{kg} / \mathrm{m}^{2}$ & $25.09 \pm 6.09$ \\
\hline Maternal age at birth in years, mean \pm SD & $30.56 \pm 5.32$ \\
\hline Obesity, BMI $\geq 30$ kg/m², yes,\#(\%) & $122,494(17.35)$ \\
\hline ART conception, yes, \#(\%) & $25,408(3.16)$ \\
\hline Maternal smoking or social drug use or alcohol consumption, yes, \#(\%) & $96,313(12.27)$ \\
\hline Maternal smoking, yes, \#(\%) & $79,502(10.27)$ \\
\hline Maternal alcohol consumption, yes,\#(\%) & $17,652(2.33)$ \\
\hline Maternal social drug use, yes, \#(\%) & $17,256(2.27)$ \\
\hline All types of mental health illness in pre-pregnancy or during pregnancy, yes, \#(\%) & $119,522(14.86)$ \\
\hline Schizophrenia or bipolar diseases in pre-pregnancy or during pregnancy, yes, \#(\%) & $4482(0.56)$ \\
\hline Depression in pre-pregnancy or during pregnancy, yes, \#(\%) & $59,306(7.37)$ \\
\hline Anxiety in pre-pregnancy or during pregnancy, yes, \#(\%) & $67,139(8.35)$ \\
\hline Pre_maternal health condition, yes, \#(\%) & $149,593(18.6)$ \\
\hline Chronic hypertension, yes, \#(\%) & $7464(0.93)$ \\
\hline Type I or type II diabetes, yes, \#(\%) & $8769(1.09)$ \\
\hline History of heart disease, yes, \#(\%) & $16,564(2.06)$ \\
\hline History of pulmonary disease, yes, \#(\%) & $31,300(3.89)$ \\
\hline History of endocrine disease, yes, \#(\%) & $39,792(4.95)$ \\
\hline Baby sex, male, \#(\%) & $412,809(51.38)$ \\
\hline Baby GA at birth, mean \pm SD & $38.79 \pm 2.12$ \\
\hline Rural residence, yes, \#(\%) & $93,402(11.7)$ \\
\hline
\end{tabular}

*Missing values were excluded for \% calculation

Abbreviations: $A R T$ assisted reproductive technology, $B M I$ body mass index, SD standard deviation, GA gestational age 
Table 2 Distributions of SES, minority and immigration status indicators categorized into quintiles at a DA level in Ontario, Canada

Variable $^{\text {a }}$
Median household income after tax adjusted by size
of household
Missing
Q1 (lowest)
Q2
Q3
Q4
Q5 (highest)

Median household income before tax adjusted by size of household

Missing
Q1 (lowest)
Q2
Q3
Q4
Q5 (highest)

Median household income after tax

$$
\begin{aligned}
& \text { Missing } \\
& \text { Q1 (lowest) } \\
& \text { Q2 } \\
& \text { Q3 } \\
& \text { Q4 } \\
& \text { Q5 (highest) }
\end{aligned}
$$

Total
number

$\begin{array}{llll}22,514 & 2.8 & 270 & 1.20 \\ 193,099 & 24.01 & 2571 & 1.33 \\ 161,321 & 20.06 & 2041 & 1.27 \\ 158,058 & 19.65 & 1794 & 1.14 \\ 147,314 & 18.32 & 1720 & 1.17 \\ 121,986 & 15.17 & 1335 & 1.09\end{array}$

Median household income before tax

$$
\begin{aligned}
& \text { Missing } \\
& \text { Q1 (lowest) } \\
& \text { Q2 } \\
& \text { Q3 } \\
& \text { Q4 } \\
& \text { Q5(highest) }
\end{aligned}
$$

Percentage of children aged 0-17 with low income

$$
\text { Missing }
$$$$
\text { Q1 (lowest) }
$$$$
\text { Q2 }
$$$$
\text { Q3 }
$$$$
\text { Q4 }
$$$$
\text { Q5 (highest) }
$$

Percentage of children aged 0-5 with low income

$$
\begin{aligned}
& \text { Missing } \\
& \text { Q1 (lowest) } \\
& \text { Q2 } \\
& \text { Q3 } \\
& \text { Q4 } \\
& \text { Q5 (highest) }
\end{aligned}
$$

Percentage of all people with low income

$$
\text { Missing }
$$

Q1 (lowest)

Q2

Percent (\%)

(\%)

Number of
CHD

of

\begin{tabular}{l} 
Percent \\
CHD $(\%)$ \\
\hline \\
1.20 \\
1.33 \\
1.27 \\
1.14 \\
1.17 \\
1.09
\end{tabular}

Percent of

22,514

190,821

159,896

160,122

146,891

124,048

22,514

173,182

155,121

153,183

164,328

135,964

22,514

175,295

154,347

151,767

164,083

136,286

32,269

129,282

151,539

151,448

150,422

189,332

32,487

154,439

131,720

188,274

140,413

156,959

32,233

123,415

152,352

2.8

23.73

19.88

19.91

18.26

15.42

2.8

21.53

19.29

19.05

20.43

16.9

2.8

21.79

19.19

18.87

20.4

16.94

4.01

16.07

18.84

18.83

18.7

23.54

4.04

19.2

16.38

23.41

17.46

19.52

4.01

15.34

18.94
CHD

D (\%)

1.09

1.20

270

2565

2034

1815

1712

1335

270

2451

1896

1896

1781

1910

1423

270

$<0.0001$

2495

1871

1805

1860

1430

$<0.0001$

$438 \quad 1.36$

1520

1740

1752

1757

2524

$<0.0001$

439

1860

1456

2121

1654

2201

$<0.0001$

trend $^{*}$
$<0.0001$

$<0.0001$

$<0.0001$

1.20

1.42

1.22

1.16

1.16

1.05

1.20

1.42

1.21

1.19

1.13

1.05

1.36

1.18

1.15

1.16

1.17

1.33

1.35

1.20

1.11

1.13

1.18

1.40

437

1.36

$1455 \quad 1.18$

$1787 \quad 1.17$ 
Table 2 Distributions of SES, minority and immigration status indicators categorized into quintiles at a DA level in Ontario, Canada (Continued)

\begin{tabular}{|c|c|c|c|c|c|}
\hline Variable $^{a}$ & $\begin{array}{l}\text { Total } \\
\text { number }\end{array}$ & Percent (\%) & $\begin{array}{l}\text { Number of } \\
\text { CHD }\end{array}$ & $\begin{array}{l}\text { Percent of } \\
\text { CHD (\%) }\end{array}$ & $\begin{array}{l}p \text { for } \\
\text { trend }\end{array}$ \\
\hline Q3 & 153,204 & 19.05 & 1761 & 1.15 & \\
\hline Q4 & 147,328 & 18.32 & 1664 & 1.13 & \\
\hline Q5 (highest) & 195,760 & 24.34 & 2627 & 1.34 & \\
\hline Percentage of people aged 25-64 without high school diploma & & & & & $<0.0001$ \\
\hline Missing & 22,206 & 2.76 & 264 & 1.19 & \\
\hline Q1 (lowest) & 146,990 & 18.28 & 1533 & 1.04 & \\
\hline Q2 & 161,763 & 20.11 & 1908 & 1.18 & \\
\hline Q3 & 162,290 & 20.18 & 1999 & 1.23 & \\
\hline Q4 & 151,759 & 18.87 & 1905 & 1.26 & \\
\hline Q5 (highest) & 159,284 & 19.8 & 2122 & 1.33 & \\
\hline Percentage of people aged $25-64$ had a degree of university or higher & & & & & $<0.0001$ \\
\hline Missing & 22,206 & 2.76 & 264 & 1.19 & \\
\hline Q1 (lowest) & 129,480 & 16.1 & 1862 & 1.44 & \\
\hline Q2 & 135,950 & 16.9 & 1773 & 1.30 & \\
\hline Q3 & 159,186 & 19.79 & 2009 & 1.26 & \\
\hline Q4 & 188,683 & 23.46 & 2129 & 1.13 & \\
\hline Q5 (highest) & 168,787 & 20.99 & 1694 & 1.00 & \\
\hline Percentage of immigrants & & & & & $<0.0001$ \\
\hline Missing & 22,206 & 2.76 & 264 & 1.19 & \\
\hline Q1 (lowest) & 121,601 & 15.12 & 1744 & 1.43 & \\
\hline Q2 & 115,179 & 14.32 & 1503 & 1.30 & \\
\hline Q3 & 131,853 & 16.39 & 1695 & 1.29 & \\
\hline Q4 & 174,205 & 21.66 & 1981 & 1.14 & \\
\hline Q5 (highest) & 239,248 & 29.75 & 2544 & 1.06 & \\
\hline Percentage of minority & & & & & $<0.0001$ \\
\hline Missing & 22,206 & 2.76 & 264 & 1.19 & \\
\hline Q1 (lowest) & 109,379 & 13.6 & 1539 & 1.41 & \\
\hline Q2 & 115,798 & 14.4 & 1607 & 1.39 & \\
\hline Q3 & 128,601 & 15.99 & 1617 & 1.26 & \\
\hline Q4 & 170,814 & 21.24 & 1864 & 1.09 & \\
\hline Q5 (highest) & 257,494 & 32.01 & 2840 & 1.10 & \\
\hline Percentage of unemployment among aged 15 or over & & & & & $<0.0001$ \\
\hline Missing & 22,206 & 2.76 & 264 & 1.19 & \\
\hline Q1 (lowest) & 125,616 & 15.62 & 1472 & 1.17 & \\
\hline Q2 & 167,581 & 20.84 & 1884 & 1.12 & \\
\hline Q3 & 170,043 & 21.14 & 2031 & 1.19 & \\
\hline Q4 & 159,195 & 19.79 & 1948 & 1.22 & \\
\hline Q5 (highest) & 159,651 & 19.85 & 2132 & 1.34 & \\
\hline Percentage of employment among aged 15 or over & & & & & $<0.0001$ \\
\hline Missing & 22,206 & 2.76 & 264 & 1.19 & \\
\hline Q1 (lowest) & 136,282 & 16.94 & 1892 & 1.39 & \\
\hline Q2 & 139,017 & 17.28 & 1710 & 1.23 & \\
\hline Q3 & 153,922 & 19.14 & 1786 & 1.16 & \\
\hline Q4 & 155,063 & 19.28 & 1884 & 1.21 & \\
\hline Q5 (highest) & 197,802 & 24.59 & 2195 & 1.11 & \\
\hline
\end{tabular}


Table 2 Distributions of SES, minority and immigration status indicators categorized into quintiles at a DA level in Ontario, Canada (Continued)

\begin{tabular}{|c|c|c|c|c|c|}
\hline Variable $^{a}$ & $\begin{array}{l}\text { Total } \\
\text { number }\end{array}$ & Percent (\%) & $\begin{array}{l}\text { Number of } \\
\text { CHD }\end{array}$ & $\begin{array}{l}\text { Percent of } \\
\text { CHD (\%) }\end{array}$ & $\begin{array}{l}p \text { for } \\
\text { trend* }\end{array}$ \\
\hline Population density per kilometer & & & & & $<0.0001$ \\
\hline Missing & 21,548 & 2.68 & 246 & 1.14 & \\
\hline Q1 (lowest) & 108,132 & 13.44 & 1413 & 1.31 & \\
\hline Q2 & 167,664 & 20.85 & 2083 & 1.24 & \\
\hline Q3 & 134,702 & 16.75 & 1685 & 1.25 & \\
\hline Q4 & 158,626 & 19.72 & 1958 & 1.23 & \\
\hline Q5 (highest) & 213,620 & 26.56 & 2346 & 1.10 & \\
\hline
\end{tabular}

${ }^{a}$ All variables were derived from Census 2016

*: $p$ value for trend test was calculated after missing values were removed

highest proportion of the study cohort was in Q4 (23.46\%) ; the CHD prevalence rate decreased from Q1 to Q5 and showed a statistically significant trend. Around one-third of the birth cohort (29.75 and $32.01 \%$, respectively) lived in neighbourhoods with the highest proportion of immigrants and minorities; for both variables, the CHD prevalence rate decreased from Q1 to Q5 and showed a statistically significant trend. This birth cohort showed that less than $20 \%$ of mothers lived in the neighbourhoods with the lowest unemployment rate, lowest employment rate and with the lowest population density. The prevalence of CHD showed an increasing trend with increasing unemployment rate and decreasing employment rate and population density.

All SES indicators show different degrees of correlations with statistical significance (Table 3). The Spearman's rankorder correlation coefficient between median household income after tax and before tax was close to one (0.98), and when adjusted by household size it was also close to one (0.98). The correlations among the percentage of all people with low income, percentage of children aged 0-17 years with low income, and percentage of children aged $0-5$ years with low income was between 0.88 and 0.75 . The correlation between the percentage of people aged 25-64 years who had a university degree or higher and without high school diploma was -0.64 . The percentage of employment among people aged 15 years or over and the percentage of unemployment among the same age group was -0.48 . The correlation between the percentage of minorities and the percentage of immigrants was 0.89 . The population density per kilometer variable had a lower correlation (0.01 to 0.34 ) with other SES indicators except with the percentage of minorities (0.59) and the percentage of immigrants $(0.57)$.

Table 4 shows both crude ORs and ORs adjusted by covariates. Compared to infants whose mothers lived in Q5 neighbourhoods (highest income), infants whose mothers lived in Q1 neighbourhoods (lowest median household income after tax) had higher likelihood of developing CHD (adjusted OR: 1.29, 95\% CI: 1.20-1.38). Compared to infants whose mothers lived in Q5 neighbourhoods (highest percentage of people with university or higher degrees among aged 25-64 population), infants whose mothers lived in Q1 neighbourhoods had higher odds of CHD (adjusted OR: 1.34, 95\% CI: 1.24-1.44). Compared to infants whose mothers lived in the neighbourhoods with the highest employment rate, infants whose mothers resided in areas with the lowest employment rate had a higher likelihood of developing CHD (adjusted OR: 1.18, 95\% CI: 1.10-1.26). Compared to infants whose mothers lived in the neighbourhoods with the lowest proportion of immigrants or minorities (Q1), infants' whose mothers resided in areas with the highest proportions of immigrants or minorities (Q5) had a lower likelihood of developing CHD; specifically, there was 18\% lower odds in Q5 immigrant neighbourhoods (adjusted OR: 0.82, 95\% CI: 0.77-0.88) and there was 16\% lower odds in Q5 minority neighbourhoods (adjusted OR: 0.84, 95\% CI: 0.78 0.91). There was no significant difference in the risk of $\mathrm{CHD}$ for infants by population density of maternal residence.

\section{Discussion}

In our study of 804,292 singletons born in hospital, 9, 731 (1.21\%) infants with CHD were identified. After adjusting for potential confounders including maternal age, maternal behavior factors, medical conditions, infant sex, and rural or urban maternal residence, we still found that certain SES variables increased the risk of $\mathrm{CHD}$, specifically those related to income, education, and employment. Compared to infants whose mothers lived in the communities with the lowest percentage of immigrants or minorities, infants had lower odds of CHD if the infants' mothers lived in the communities with the highest percentage of immigrants or minorities. No association was found between population density of maternal residence and risk of CHD. In this study, late stage terminations and births (live births and stillbirths) were combined in the analysis. Given that pregnancy outcome could be a marker of severity of CHD, we conducted a sensitivity analysis by excluding both stillbirths and terminations, as well as by excluding terminations only from the cohort. The results are very similar (Appendix B). 
Miro et al. BMC Pregnancy and Childbirth

(2021) $21: 72$

Page 9 of 21

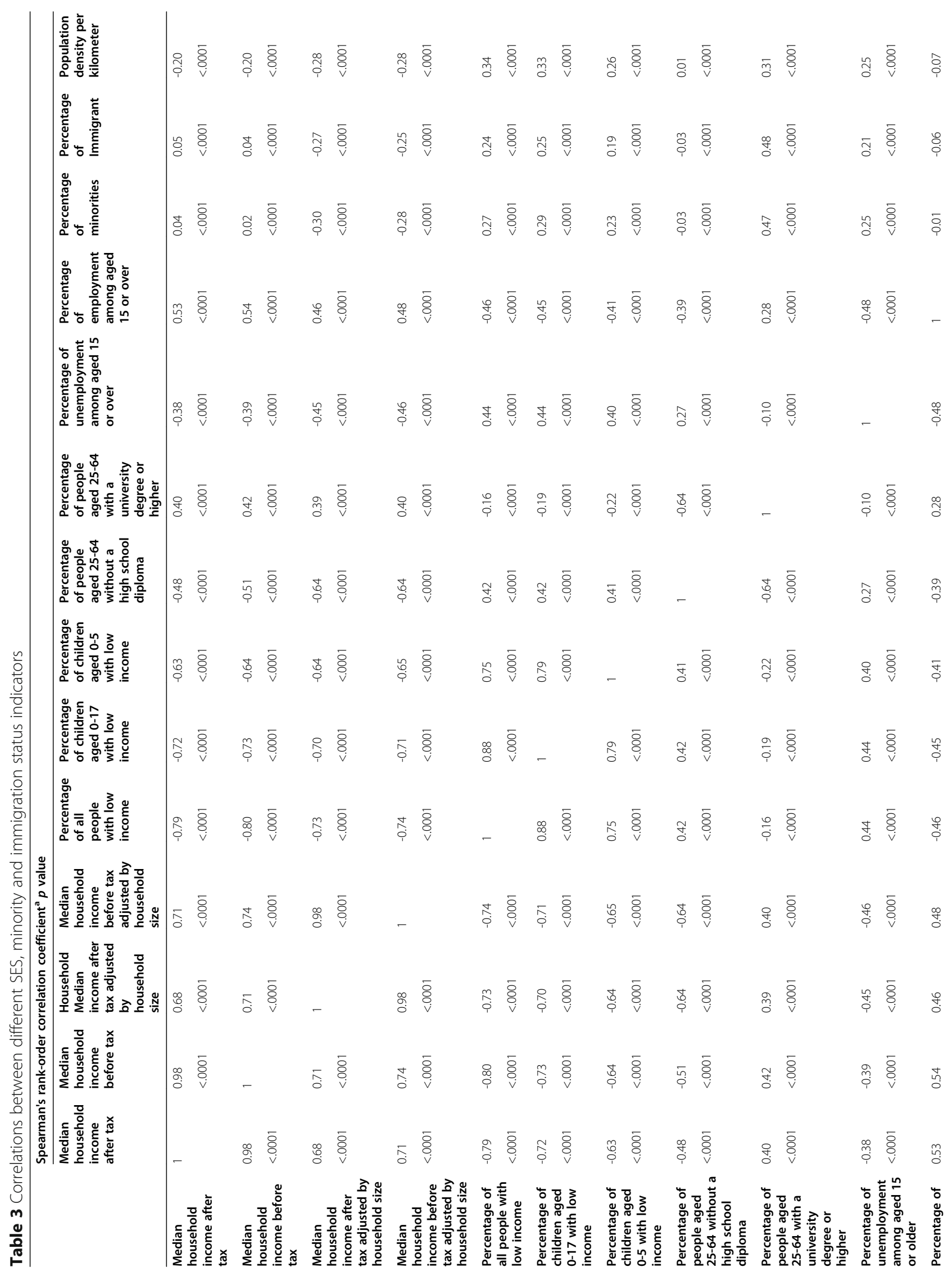




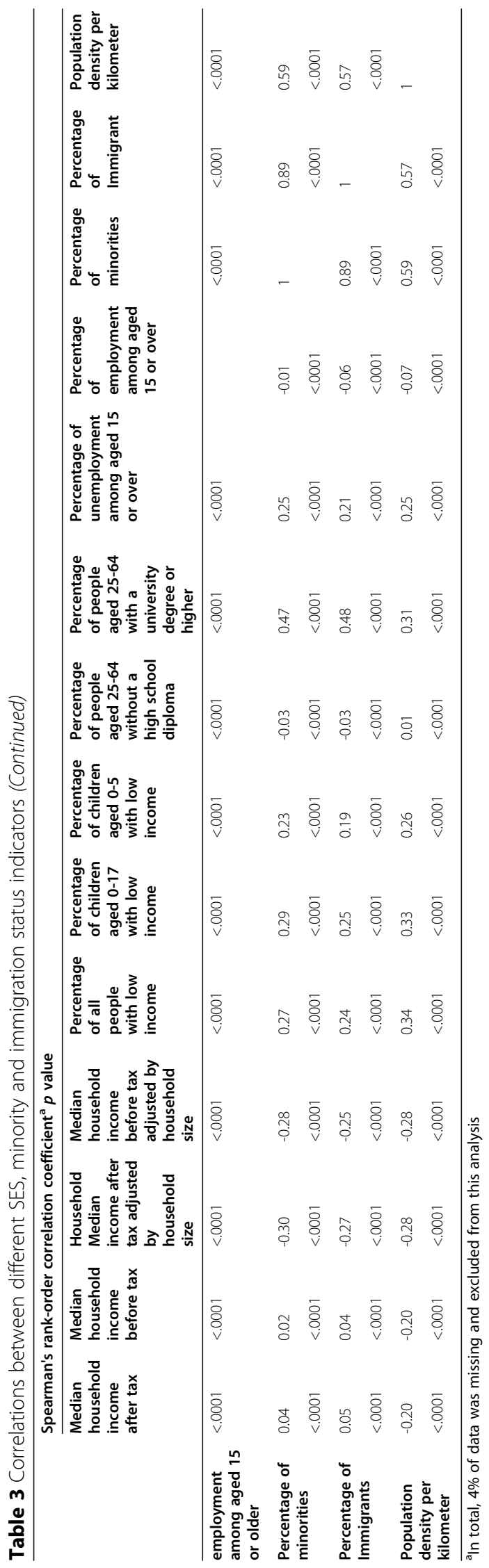


Table 4 Associations between different maternal SES, minority and immigration status indicators and CHD

\begin{tabular}{|c|c|c|}
\hline Variable & Crude OR & Adjust OR \\
\hline \multicolumn{3}{|c|}{ Median household income after tax } \\
\hline Q1 (lowest) & $1.34(1.26-1.44)$ & $1.29(1.20-1.38)$ \\
\hline Q2 & $1.18(1.1-1.26)$ & $1.13(1.05-1.22)$ \\
\hline Q3 & $1.11(1.03-1.19)$ & $1.08(1-1.16)$ \\
\hline Q4 & $1.10(1.03-1.19)$ & $1.10(1.02-1.18)$ \\
\hline Q5 (highest) & Reference & Reference \\
\hline \multicolumn{3}{|c|}{ Median household income before tax } \\
\hline Q1 (lowest) & $1.35(1.26-1.44)$ & $1.30(1.21-1.39)$ \\
\hline Q2 & $1.16(1.08-1.25)$ & $1.13(1.05-1.21)$ \\
\hline Q3 & $1.13(1.06-1.22)$ & $1.11(1.03-1.19)$ \\
\hline Q4 & $1.07(1.00-1.15)$ & $1.07(1-1.15)$ \\
\hline Q5 (highest) & Reference & Reference \\
\hline \multicolumn{3}{|c|}{ Median household income after tax adjusted by size of household } \\
\hline Q1 (lowest) & $1.17(1.09-1.25)$ & $1.18(1.10-1.27)$ \\
\hline Q2 & $1.14(1.06-1.23)$ & $1.14(1.06-1.23)$ \\
\hline Q3 & $1.03(0.95-1.1)$ & $1.02(0.95-1.1)$ \\
\hline Q4 & $1.05(0.98-1.13)$ & $1.05(0.97-1.13)$ \\
\hline Q5 (highest) & Reference & Reference \\
\hline \multicolumn{3}{|c|}{ Median household income before tax adjusted by size of household } \\
\hline Q1 (lowest) & $1.20(1.12-1.29)$ & $1.22(1.13-1.30)$ \\
\hline Q2 & $1.17(1.09-1.26)$ & $1.17(1.09-1.26)$ \\
\hline Q3 & $1.04(0.97-1.12)$ & $1.04(0.96-1.12)$ \\
\hline Q4 & $1.07(1.00-1.16)$ & $1.07(1.00-1.15)$ \\
\hline Q5 (highest) & Reference & Reference \\
\hline \multicolumn{3}{|c|}{ Percentage of all people with low income } \\
\hline Q1 (lowest) & Reference & Reference \\
\hline Q2 & $1.00(0.93-1.07)$ & $1.00(0.94-1.08)$ \\
\hline Q3 & $0.96(0.89-1.03)$ & $0.97(0.91-1.05)$ \\
\hline Q4 & $0.96(0.89-1.03)$ & $0.96(0.9-1.04)$ \\
\hline Q5 (highest) & $1.13(1.06-1.21)$ & $1.13(1.06-1.21)$ \\
\hline \multicolumn{3}{|c|}{ Percentage of children aged 0-17 with low income } \\
\hline Q1 (lowest) & Reference & Reference \\
\hline Q2 & $0.98(0.91-1.05)$ & $0.99(0.93-1.07)$ \\
\hline Q3 & $0.98(0.91-1.05)$ & $1.01(0.94-1.08)$ \\
\hline Q4 & $0.99(0.93-1.07)$ & $1.01(0.94-1.08)$ \\
\hline Q5 (highest) & $1.14(1.06-1.21)$ & $1.14(1.07-1.22)$ \\
\hline \multicolumn{3}{|c|}{ Percentage of children aged 0-5 with low income } \\
\hline Q1 (lowest) & Reference & Reference \\
\hline Q2 & $0.92(0.86-0.99)$ & $0.95(0.89-1.02)$ \\
\hline Q3 & $0.93(0.87-0.99)$ & $0.96(0.90-1.02)$ \\
\hline Q4 & $0.97(0.9-1.04)$ & $0.99(0.92-1.06)$ \\
\hline Q5 (highest) & $1.16(1.09-1.24)$ & $1.17(1.10-1.25)$ \\
\hline \multicolumn{3}{|c|}{ Percentage of people aged 25-64 with a university degree or higher } \\
\hline Q1 (lowest) & $1.42(1.32-1.52)$ & $1.34(1.24-1.44)$ \\
\hline Q2 & $1.30(1.21-1.4)$ & $1.26(1.17-1.35)$ \\
\hline Q3 & $1.25(1.17-1.34)$ & $1.24(1.16-1.33)$ \\
\hline
\end{tabular}


Table 4 Associations between different maternal SES, minority and immigration status indicators and CHD (Continued)

\begin{tabular}{|c|c|c|}
\hline Variable & Crude OR & Adjust OR \\
\hline Q4 & $1.11(1.04-1.18)$ & $1.11(1.04-1.19)$ \\
\hline Q5 (highest) & Reference & Reference \\
\hline \multicolumn{3}{|c|}{ Percentage of people aged 25-64 without a high school diploma } \\
\hline Q1 (lowest) & Reference & Reference \\
\hline Q2 & $1.10(1.03-1.18)$ & $1.10(1.02-1.18)$ \\
\hline Q3 & $1.16(1.08-1.24)$ & $1.14(1.07-1.23)$ \\
\hline Q4 & $1.18(1.1-1.27)$ & $1.16(1.08-1.25)$ \\
\hline Q5 (highest) & $1.24(1.16-1.33)$ & $1.21(1.13-1.3)$ \\
\hline \multicolumn{3}{|c|}{ Percentage of unemployment among aged 15 or over } \\
\hline Q1 (lowest) & Reference & Reference \\
\hline Q2 & $0.95(0.89-1.02)$ & $0.96(0.90-1.03)$ \\
\hline Q3 & $1.00(0.93-1.07)$ & $1.02(0.95-1.09)$ \\
\hline Q4 & $1.03(0.96-1.1)$ & $1.05(0.98-1.12)$ \\
\hline Q5 (highest) & $1.09(1.02-1.17)$ & $1.09(1.02-1.17)$ \\
\hline \multicolumn{3}{|c|}{ Percentage of employment among aged 15 or over } \\
\hline Q1 (lowest) & $1.22(1.15-1.30)$ & $1.18(1.10-1.26)$ \\
\hline Q2 & $1.11(1.04-1.18)$ & $1.09(1.02-1.16)$ \\
\hline Q3 & $1.05(0.98-1.12)$ & $1.04(0.98-1.11)$ \\
\hline Q4 & $1.10(1.03-1.17)$ & $1.09(1.02-1.16)$ \\
\hline Q5(highest) & Reference & Reference \\
\hline \multicolumn{3}{|c|}{ Percentage of minorities } \\
\hline Q1 (lowest) & Reference & Reference \\
\hline Q2 & $1.01(0.94-1.09)$ & $0.99(0.92-1.07)$ \\
\hline Q3 & $0.92(0.85-0.99)$ & $0.90(0.83-0.98)$ \\
\hline Q4 & $0.79(0.74-0.85)$ & $0.80(0.74-0.87)$ \\
\hline Q5 (highest) & $0.78(0.73-0.84)$ & $0.84(0.78-0.91)$ \\
\hline \multicolumn{3}{|c|}{ Percentage of immigrants } \\
\hline Q1 (lowest) & Reference & Reference \\
\hline Q2 & $0.93(0.87-1.00)$ & $0.94(0.88-1.01)$ \\
\hline Q3 & $0.92(0.86-0.99)$ & $0.94(0.87-1.01)$ \\
\hline Q4 & $0.81(0.76-0.87)$ & $0.86(0.79-0.92)$ \\
\hline Q5 (highest) & $0.74(0.69-0.79)$ & $0.82(0.77-0.88)$ \\
\hline \multicolumn{3}{|c|}{ Population density per kilometer } \\
\hline Q1 (lowest) & Reference & Reference \\
\hline Q2 & $0.98(0.91-1.05)$ & $1.05(0.94-1.18)$ \\
\hline Q3 & $0.98(0.91-1.06)$ & $1.05(0.93-1.18)$ \\
\hline Q4 & $0.97(0.9-1.04)$ & $1.05(0.93-1.19)$ \\
\hline Q5 (highest) & $0.86(0.8-0.92)$ & $0.96(0.85-1.08)$ \\
\hline
\end{tabular}

Note. Multivariable logistic regression models were performed to calculate adjusted ORs. Adjusted ORs for each SES variable were in one separate model adjusting for covariates including maternal age at birth, pre-pregnancy obesity, maternal smoking or social drug use or alcohol consumption, mental health illness in pre-pregnancy or during pregnancy, pre-pregnancy maternal health condition, infant sex and maternal residence in rural area

This large population-based birth cohort represents all singleton hospital births in Ontario from the fiscal years of 2012 (April 1, 2012 - March 31, 2013) to 2017 (April 1, 2017 - March 31, 2018). We identified prenatal and postnatal CHD cases (up to the first year of life) by linking multiple databases. The overall
CHD prevalence rate (1.21 per 100 births) that we observed was consistent with that reported in the literature in Canada and worldwide [1,3-6]. A study using national CIHI data (excluding the province of Quebec) reported that the CHD prevalence between 1990 and 2011 was 12.3 per 1000 live births and 
stillbirths [8,9]. Another study that used CIHI data between 1994 and 2007 found a prevalence rate of 15.1 per 1000 live births [14].

In our study, we examined the relationships between different community median household income-related SES variables and the risk of CHD. Compared to infants whose mothers lived in Q5 neighbourhoods, the odds of having a CHD among infants whose mothers resided in Q1, Q2, Q3 and Q4 were similar using the variables of 'median household income after tax' or 'median household income before tax'. The median household income after tax variable should be more accurate than the one before tax because the former reflects the actual income that a household receives. However, we used quintiles of household income at a DA level, thereby minimizing the actual difference. In terms of median household income or median household income adjusted by size of household, the ORs of CHD among infants was higher for Q1 neighbourhoods compared to Q5 neighbourhoods (OR: 1.29, 1.30, 1.18 and 1.22 for median household income after tax, median household income before tax, median household income after tax adjusted by size of household and median household income before tax adjusted by size of household, respectively). The ORs for the other categories (Q2 vs. Q5, Q3 vs. Q5, and Q4 vs. Q5) were similar for these four variables. Median household income unadjusted by household size is more frequently used in research. There was no consensus if we should have used median household income or median household income adjusted by household size, as none of them capture the actual financial condition of the household. Through examining these four indicators, we concluded that the most significant effect on the risk of CHD occurred in the least wealthy areas. This finding is consistent with that in the literature [12].

In terms of the three poverty indicators (percentage of all people with low income, percentage of children aged $0-17$ years with low income and percentage of children aged $0-5$ years with low income), they all showed a similar pattern. Infants whose mother resided in an area with the highest percentage of people with low income (Q5) had a higher risk of CHD when compared to infants whose mother lived in an area with the lowest percentage of people with low income $(\mathrm{Q} 1)$.

All household income variables and poverty indicators are related with families' material resources. A family with a lower income may only be able to afford to live in an area with disadvantaged living environments such as high pollution and less green space [36]. Rented homes may be associated with poor indoor air quality [36]. Furthermore, lower income families may only be able to afford lower quality food. Poorer financial conditions may increase stress levels as well, which could increase the risk of CHD [20,21].

Regarding education level indicators (percentage of people aged 25-64 years without a high school diploma and percentage of people aged 25-64 years with a university degree or higher), there was a higher risk of CHD among infants when the education level of those in the household was lower. Lower education level may be a proxy of lack of knowledge on prevention of adverse maternal and birth outcomes including healthy diet and physical activity etc., which we were not able to measure in the analysis due to data limitations. In addition, a lower education level tends to be correlated with a lower income [27]. Thus, any mechanisms through which lower family income lead to a higher risk of CHD may also apply to education indicators.

Unemployment and employment rates also show a similar pattern with household income and education indicators. Employment or unemployment status influences a household's income, which may be directly related to a family's purchasing power for housing with higher quality living conditions, healthy foods and maintaining healthy behaviors [27, 39].

Minority and immigrant groups are often characterized as socially disadvantaged groups because most of them, especially newcomers, likely lack social and financial support and have underdeveloped social connections [39]. This could increase maternal stress levels and thus potentially elevate the risk of adverse birth outcomes $[20,21,36]$. However, in our study, the findings of minority and immigrant indicators on the risk of CHD are in the opposite direction than expected. One recent published study also found similar results using Ontario hospital births and refugee/immigrant population-based data between April 1, 2002 and March 31, 2014 [40]. The study showed that compared to Canadian-born pregnant women, non-refugee immigrants (adjusted OR: 0.86, 95\% CI: $0.84-0.88$ ) and refugee immigrants (adjusted OR: 0.87, 95\% CI: 0.83-0.91) had lower odds of having a child with congenital anomalies [40]. The unexpected finding may be due to the healthy immigrant effect [41]. In Canada, many minorities are recent immigrants [29]. A number of studies have shown that the health of recently immigrated women is better than the health of Canadian-born women and the women in the original countries where these immigrants are from [41]. This healthy immigrant effect may be due to the Canadian government's selection of healthy immigrants and immigrants' "self-selection of healthier individuals" from their mother countries [41]. In addition, new immigrants may tend to have healthier behaviors including no smoking, less alcohol and drug consumption, physical activity 
and healthy diets [41, 42]. To further investigate the relationships between immigrants and minorities and the risk of CHD in infants, an individual-level analysis is needed as the indicators of minorities and immigrants at a community level may not represent the true relationships with the risk of CHD [43].

This study had several strengths. We included all singleton births from fiscal year 2012-13 to fiscal year 2017-18 in the province of Ontario, Canada. The large sample size improved the precision of the study results. The prevalence of CHD represented the target population of Ontario. Furthermore, the CHD cases were ascertained by linking multiple data sources including those identified in prenatal, postnatal or birth records and those identified up to 1 year of infancy. Many other studies using birth registry data lacked sufficient resources to conduct analysis on the complete data.

There were a few limitations in this study. First, due to data limitations, we were not able to use the individual family's household income, the mother's education level and employment status to evaluate the relationships between the maternal SES factors and the risk of CHD among infants. Instead, we had to rely on information from the neighbourhoods in which mothers resided. However, in Canada, neighbourhood SES factors are based on the DA level (a small geographic area, including 400-700 persons) and have been considered as good proxies of individual-level maternal SES factors as reported in previous studies [44]. The findings of our study are consistent with that from studies using individual-level SES indicators[12, 45, 46]. For example, one case-control study conducted in Lithuania found that compared to mothers who received advanced vocational training or higher education, those mothers who received low and moderate education levels were 3.4 times more likely to have a child with CHD [45]. Another study conducted in China found low household income and mothers without a high school diploma were associated with certain types of $\mathrm{CHD}$, including ventricular septal defect, atrial septal defect and pulmonary stenosis [46].

In addition, neighbourhood SES variables may also reflect the conditions of external environmental factors and accessibility to social and health services that might influence the prevalence of CHD. For example, living in a neighbourhood with lower SES may imply a disadvantaged outdoor living environment characterized by higher air pollution; lack of access to health care services, parks and green spaces, and stores with healthy food options; and lack of social support [13, 36]. For the community-level indicators of immigrant and ethnicity status, we were not able to examine the variation of CHD risk by race/ethnic group and type of immigrants. Future studies should focus on investigating the relationships between immigrant and minority status and the risk of CHD using individual-level measurement, including ethnic group and immigration status. Moreover, although all possible CHD records were obtained from the birth registry and health administrative data, it is important to note that these data are not for the sole purpose of specific research projects. Therefore, there is the potential that some CHD outcomes were misclassified. Finally, in this study, there was about $4 \%$ of the study cohort without community-level values for at least one of these SES variables due to unstable populations, absent census data, or missing maternal postal codes.

In summary, this study found that lower household income, unemployment status and living in poverty could increase the risk of CHD. Similarly, mothers with a lower education level had an increased risk of an infant with CHD. All four median household income and two education related SES indicators showed this trend and a dose response effect. Population density is not related with the risk of CHD. Immigrant and minority status could be potential protective factors, which may suggest a healthy immigrant effect.

\section{Conclusions}

Low maternal neighbourhood household income, poverty, lower education level, and unemployment status increase the risk of CHD, highlighting a significant social inequity in Ontario Canada. This suggests that health interventions and policies should target lower SES families. Immigration and minority status are potential protective factors, which implies a healthy immigrant effect. Further studies are required to confirm this finding by analyzing individuallevel data on immigration and minority status.

\section{Appendices}

Appendix A

a) CHD diagnosis and classification of diseases in ICD-10-CA

Q20 Congenital malformations of cardiac chambers and connections.

Q21 Congenital malformations of cardiac septa (excluding patent foramen ovale in Q21.1).

Q22 Congenital malformations of pulmonary and tricuspid valves.

Q23 Congenital malformations of aortic and mitral valves.

Q24 Other congenital malformations of heart including Q24.0, Q24.2 to Q24.5, Q24.8, Q24.9,

Q25: Congenital malformations of great arteries including Q25.1 to Q25.9.

Q26 Congenital malformations of great veins, including Q26.0 to Q26.4. 


\section{b) Picklist values in the BIS data}

Truncus arteriosis

Double outlet ventricle (DOV)

Transposition of great vessels (TGA)

Transposition of great arteries - congenitally corrected (CCTGA)

Double inlet ventricle (DIV)

Single outlet ventricle

Single ventricle (univentricular heart)

Single ventricle / univentricular connection

Ivemark Syndrome

Ventricular septal defect (VSD)

Atrial septal defect (ASD)

Common atrium

Atrioventricular septal defect (AVSD) (endocardial cushion defect)

Tetralogy of Fallot (TOF)

Aorta - pulmonary window

Tricuspid valve dysplasia

Valvular Anomalies

Pulmonary (valve) atresia

Pulmonary (valve) stenosis (PS)

Pulmonary insufficiency

Tricuspid atresia

Tricuspid stenosis

Ebstein anomaly

Hypoplastic right heart syndrome (HRHS)

Aortic valve stenosis

Aortic valve insufficiency

Mitral stenosis

Mitral regurgitation

Mitral valve dysplasia

HLHS (hypoplastic left heart syndrome)

Hypoplastic left heart syndrome (HLHS)

Other - cardiac malformations not classified elsewhere

Dextrocardia

Dextrocardia

Subaortic stenosis

Coronary artery fistula

Cardiomegaly

Cardiomyopathy - dilated

Cardiomyopathy - fetus of diabetic mother

Cardiomyopathy - hypertrophic (HOCM)

Diverticulum - LV

Diverticulum - RV

Ectopia cordis

Pericardial/Paracardial cyst

\section{Appendix A (Continued)}

Pulmonary valve dysplasia

Coarctation of aorta

Shone's syndrome

Aortic arch - interrupted

Aortic atresia

Aortic arch - double

Dilated ascending aorta

Aortic arch - hypoplastic

Right aortic arch

Vascular ring

Vein of Galen aneurysm

Persistent left SVC (superior vena cava)

Total anomalous pulmonary venous drainage (TAPVD)

Partial anomalous pulmonary venous drainage (PAPVD)

Bilateral SVC (superior venae cava)

Left atrial isomerism (heterotaxy)

Right atrial isomerism (heterotaxy)

Scimitar syndrome

Interrupted IVC (superior vena cava) 


\section{Appendix B. Sensitivity analysis}

Table 5 Associations between different maternal SES, minority and immigration status indicators and CHD (excluding terminations and stillbirths)

\begin{tabular}{|c|c|c|}
\hline Variable & Crude OR & Adjust OR \\
\hline \multicolumn{3}{|c|}{ Median household income after tax } \\
\hline Q1 (lowest) & $1.35(1.26-1.45)$ & $1.29(1.20-1.39)$ \\
\hline Q2 & $1.20(1.11-1.29)$ & $1.15(1.07-1.24)$ \\
\hline Q3 & $1.13(1.05-1.21)$ & $1.09(1.01-1.18)$ \\
\hline Q4 & $1.12(1.04-1.2)$ & $1.11(1.03-1.19)$ \\
\hline Q5 (highest) & Reference & Reference \\
\hline \multicolumn{3}{|c|}{ Median household income before tax } \\
\hline Q1 (lowest) & $1.36(1.27-1.45)$ & $1.31(1.22-1.4)$ \\
\hline Q2 & $1.19(1.11-1.28)$ & $1.15(1.07-1.24)$ \\
\hline Q3 & $1.15(1.07-1.24)$ & $1.12(1.04-1.21)$ \\
\hline Q4 & $1.09(1.01-1.17)$ & $1.09(1.01-1.17)$ \\
\hline Q5 (highest) & Reference & Reference \\
\hline \multicolumn{3}{|c|}{ Median household income after tax adjusted by size of household } \\
\hline Q1 (lowest) & $1.19(1.11-1.27)$ & $1.20(1.12-1.29)$ \\
\hline Q2 & $1.16(1.08-1.25)$ & $1.16(1.08-1.25)$ \\
\hline Q3 & $1.04(0.97-1.12)$ & $1.04(0.96-1.12)$ \\
\hline Q4 & $1.06(0.99-1.15)$ & $1.06(0.98-1.14)$ \\
\hline Q5 (highest) & Reference & Reference \\
\hline \multicolumn{3}{|c|}{ Median household income before tax adjusted by size of household } \\
\hline Q1 (lowest) & $1.22(1.14-1.31)$ & $1.23(1.15-1.33)$ \\
\hline Q2 & $1.20(1.11-1.29)$ & $1.19(1.11-1.29)$ \\
\hline Q3 & $1.06(0.98-1.14)$ & $1.05(0.97-1.13)$ \\
\hline Q4 & $1.09(1.01-1.17)$ & $1.09(1.01-1.17)$ \\
\hline Q5 (highest) & Reference & Reference \\
\hline \multicolumn{3}{|c|}{ Percentage of all people with low income } \\
\hline Q1 (lowest) & Reference & Reference \\
\hline Q2 & $0.99(0.92-1.07)$ & $1.00(0.93-1.07)$ \\
\hline Q3 & $0.97(0.90-1.04)$ & $0.98(0.91-1.05)$ \\
\hline Q4 & $0.96(0.89-1.03)$ & $0.96(0.90-1.04)$ \\
\hline Q5 (highest) & $1.13(1.06-1.21)$ & $1.13(1.05-1.21)$ \\
\hline \multicolumn{3}{|c|}{ Percentage of children aged 0-17 with low income } \\
\hline Q1 (lowest) & Reference & Reference \\
\hline Q2 & $0.98(0.91-1.06)$ & $1.00(0.93-1.07)$ \\
\hline Q3 & $0.99(0.92-1.06)$ & $1.02(0.95-1.09)$ \\
\hline Q4 & $1.00(0.93-1.08)$ & $1.02(0.95-1.1)$ \\
\hline Q5 (highest) & $1.14(1.06-1.22)$ & $1.15(1.07-1.23)$ \\
\hline \multicolumn{3}{|c|}{ Percentage of children aged 0-5 with low income } \\
\hline Q1 (lowest) & Reference & Reference \\
\hline Q2 & $0.92(0.86-0.99)$ & $0.96(0.89-1.03)$ \\
\hline Q3 & $0.93(0.88-1.00)$ & $0.96(0.90-1.03)$ \\
\hline Q4 & $0.97(0.91-1.04)$ & $0.99(0.93-1.07)$ \\
\hline Q5 (highest) & $1.16(1.09-1.24)$ & $1.17(1.10-1.25)$ \\
\hline
\end{tabular}

Percentage of people aged 25-64 with a university degree or higher 
Table 5 Associations between different maternal SES, minority and immigration status indicators and CHD (excluding terminations and stillbirths) (Continued)

\begin{tabular}{|c|c|c|}
\hline Variable & Crude OR & Adjust OR \\
\hline Q1 (lowest) & $1.46(1.36-1.56)$ & $1.37(1.27-1.48)$ \\
\hline Q2 & $1.33(1.24-1.43)$ & $1.28(1.19-1.38)$ \\
\hline Q3 & $1.27(1.19-1.36)$ & $1.26(1.17-1.35)$ \\
\hline Q4 & $1.11(1.03-1.19)$ & $1.11(1.04-1.19)$ \\
\hline Q5 (highest) & Reference & Reference \\
\hline \multicolumn{3}{|c|}{ Percentage of people aged 25-64 without a high school diploma } \\
\hline Q1 (lowest) & Reference & Reference \\
\hline Q2 & $1.11(1.03-1.19)$ & $1.11(1.03-1.19)$ \\
\hline Q3 & $1.17(1.09-1.25)$ & $1.15(1.07-1.24)$ \\
\hline Q4 & $1.20(1.12-1.29)$ & $1.18(1.09-1.26)$ \\
\hline Q5 (highest) & $1.27(1.18-1.36)$ & $1.23(1.14-1.32)$ \\
\hline \multicolumn{3}{|c|}{ Percentage of unemployment among aged 15 or over } \\
\hline Q1 (lowest) & Reference & Reference \\
\hline Q2 & $0.94(0.87-1.01)$ & $0.95(0.88-1.02)$ \\
\hline Q3 & $0.99(0.92-1.06)$ & $1.01(0.94-1.08)$ \\
\hline Q4 & $1.02(0.95-1.09)$ & $1.04(0.97-1.12)$ \\
\hline Q5 (highest) & $1.08(1.01-1.16)$ & $1.09(1.01-1.17)$ \\
\hline \multicolumn{3}{|c|}{ Percentage of employment among aged 15 or over } \\
\hline Q1 (lowest) & $1.22(1.14-1.3)$ & $1.17(1.1-1.25)$ \\
\hline Q2 & $1.1(1.03-1.18)$ & $1.08(1.01-1.16)$ \\
\hline Q3 & $1.04(0.97-1.11)$ & $1.03(0.97-1.1)$ \\
\hline Q4 & $1.10(1.03-1.17)$ & $1.09(1.02-1.16)$ \\
\hline Q5 (highest) & Reference & Reference \\
\hline \multicolumn{3}{|c|}{ Percentage of minorities } \\
\hline Q1 (lowest) & Reference & Reference \\
\hline Q2 & $1.02(0.94-1.09)$ & $1.00(0.92-1.08)$ \\
\hline Q3 & $0.91(0.84-0.98)$ & $0.90(0.83-0.97)$ \\
\hline Q4 & $0.79(0.73-0.85)$ & $0.80(0.74-0.87)$ \\
\hline Q5 (highest) & $0.78(0.73-0.83)$ & $0.84(0.77-0.91)$ \\
\hline \multicolumn{3}{|c|}{ Percentage of immigrants } \\
\hline Q1 (lowest) & Reference & Reference \\
\hline Q2 & $0.94(0.87-1.01)$ & $0.95(0.88-1.02)$ \\
\hline Q3 & $0.91(0.85-0.98)$ & $0.94(0.87-1.01)$ \\
\hline Q4 & $0.80(0.75-0.86)$ & $0.85(0.79-0.92)$ \\
\hline Q5 (highest) & $0.74(0.69-0.79)$ & $0.83(0.77-0.89)$ \\
\hline \multicolumn{3}{|c|}{ Population density per kilometer } \\
\hline Q1 (lowest) & Reference & Reference \\
\hline Q2 & $0.96(0.9-1.04)$ & $1.04(0.92-1.17)$ \\
\hline Q3 & $0.98(0.91-1.06)$ & $1.05(0.93-1.19)$ \\
\hline Q4 & $0.95(0.89-1.03)$ & $1.04(0.92-1.18)$ \\
\hline Q5 (highest) & $0.85(0.79-0.91)$ & $0.96(0.85-1.08)$ \\
\hline
\end{tabular}

Note. Multivariable logistic regression models were performed to calculate adjusted ORs. Adjusted ORs for each SES variable were in one separate model adjusting for covariates including maternal age at birth, pre-pregnancy obesity, maternal smoking or social drug use or alcohol consumption, mental health illness in pre-pregnancy or during pregnancy, pre-pregnancy maternal health condition, infant sex and maternal residence in rural area 
Table 6 Associations between SES variables, minority and immigration status and the risk of CHD (excluding terminations)

\begin{tabular}{ll}
\hline Variable & Crude OR \\
\hline Median household income after tax & \\
Q1 (lowest) & $1.35(1.26-1.45)$ \\
Q2 & $1.20(1.11-1.29)$ \\
Q3 & $1.13(1.05-1.21)$ \\
Q4 & $1.12(1.04-1.20)$ \\
Q5 (highest) & Reference \\
Median household income before tax & \\
Q1 (lowest) & $1.36(1.27-1.45)$ \\
Q2 & $1.19(1.11-1.28)$ \\
Q3 & $1.15(1.07-1.24)$ \\
Q4 & $1.09(1.01-1.17)$ \\
Q5 (highest) & Reference
\end{tabular}

Adjust OR

$1.29(1.20-1.39)$

$1.15(1.07-1.24)$

$1.09(1.01-1.18)$

1.11 (1.03-1.19)

Reference

$1.31(1.22-1.4)$

1.15 (1.07-1.24)

$1.12(1.04-1.21)$

$1.09(1.01-1.17)$

Reference

$1.20(1.12-1.29)$

$1.16(1.08-1.25)$

$1.04(0.96-1.12)$

$1.06(0.98-1.14)$

Reference

$1.23(1.15-1.33)$

$1.19(1.11-1.29)$

1.05 (0.97-1.13)

1.09 (1.01-1.17)

Reference

Reference

1.00 (0.93-1.07)

$0.98(0.91-1.05)$

$0.96(0.9-1.04)$

$1.13(1.05-1.21)$

Reference

$1.00(0.93-1.07)$

$1.02(0.95-1.09)$

$1.02(0.95-1.1)$

$1.15(1.07-1.23)$

$1.37(1.27-1.48)$

$1.28(1.19-1.38)$

1.26 (1.17-1.35)

1.11 (1.04-1.19)

Reference 
Table 6 Associations between SES variables, minority and immigration status and the risk of CHD (excluding terminations) (Continued)

\begin{tabular}{|c|c|c|}
\hline Variable & Crude OR & Adjust OR \\
\hline \multicolumn{3}{|c|}{ Percentage of people aged 25-64 without a high school diploma } \\
\hline Q1 (lowest) & Reference & Reference \\
\hline Q2 & $1.11(1.03-1.19)$ & $1.11(1.03-1.19)$ \\
\hline Q3 & $1.17(1.09-1.25)$ & $1.15(1.07-1.24)$ \\
\hline Q4 & $1.20(1.12-1.29)$ & $1.18(1.09-1.26)$ \\
\hline Q5 (highest) & $1.27(1.18-1.36)$ & $1.23(1.14-1.32)$ \\
\hline \multicolumn{3}{|c|}{ Percentage of unemployment among aged 15 or over } \\
\hline Q1 (lowest) & Reference & Reference \\
\hline Q2 & $0.94(0.87-1.01)$ & $0.95(0.88-1.02)$ \\
\hline Q3 & $0.99(0.92-1.06)$ & $1.01(0.94-1.08)$ \\
\hline Q4 & $1.02(0.95-1.09)$ & $1.04(0.97-1.12)$ \\
\hline Q5 (highest) & $1.08(1.01-1.16)$ & $1.09(1.01-1.17)$ \\
\hline \multicolumn{3}{|c|}{ Percentage of employment among aged 15 or over } \\
\hline Q1 (lowest) & $1.22(1.14-1.3)$ & $1.17(1.1-1.25)$ \\
\hline Q2 & $1.10(1.03-1.18)$ & $1.08(1.01-1.16)$ \\
\hline Q3 & $1.04(0.97-1.11)$ & $1.03(0.97-1.1)$ \\
\hline Q4 & $1.10(1.03-1.17)$ & $1.09(1.02-1.16)$ \\
\hline Q5 (highest) & Reference & Reference \\
\hline \multicolumn{3}{|c|}{ Percentage of minorities } \\
\hline Q1 (lowest) & Reference & Reference \\
\hline Q2 & $1.02(0.94-1.09)$ & $1.00(0.92-1.08)$ \\
\hline Q3 & $0.91(0.84-0.98)$ & $0.90(0.83-0.97)$ \\
\hline Q4 & $0.79(0.73-0.85)$ & $0.80(0.74-0.87)$ \\
\hline Q5 (highest) & $0.78(0.73-0.83)$ & $0.84(0.77-0.91)$ \\
\hline \multicolumn{3}{|c|}{ Percentage of immigrants } \\
\hline Q1 (lowest) & Reference & Reference \\
\hline Q2 & $0.94(0.87-1.01)$ & $0.95(0.88-1.02)$ \\
\hline Q3 & $0.91(0.85-0.98)$ & $0.94(0.87-1.01)$ \\
\hline Q4 & $0.80(0.75-0.86)$ & $0.85(0.79-0.92)$ \\
\hline Q5 (highest) & $0.74(0.69-0.79)$ & $0.83(0.77-0.89)$ \\
\hline \multicolumn{3}{|c|}{ Population density per kilometer } \\
\hline Q1 (lowest) & Reference & Reference \\
\hline Q2 & $0.96(0.9-1.04)$ & $1.04(0.92-1.17)$ \\
\hline Q3 & $0.98(0.91-1.06)$ & $1.05(0.93-1.19)$ \\
\hline Q4 & $0.95(0.89-1.03)$ & $1.04(0.92-1.18)$ \\
\hline Q5 (highest) & $0.85(0.79-0.91)$ & $0.96(0.85-1.08)$ \\
\hline
\end{tabular}

Note. Multivariable logistic regression models were performed to calculate adjusted ORs. Adjusted ORs for each SES variable were in one separate model adjusting for covariates including maternal age at birth, pre-pregnancy obesity, maternal smoking or social drug use or alcohol consumption, mental health illness in pre-pregnancy or during pregnancy, pre-pregnancy maternal health condition, infant sex and maternal residence in rural area

\section{Abbreviations}

CHD: Congenital heart disease; SES: Socioeconomic status; PCCF+: Postal Code Conversion File Plus; DA: Dissemination area; BORN: Better Outcomes Registry \& Network; CIHI: Canadian Institute for Health Information; DAD: Discharge

Abstract Database; CIHI-DAD: The Canadian Institute for Health Information Discharge Abstract Database; CAs: Congenital anomalies; ART: Assisted reproductive technology; BIS: BORN Information System; NACRS: National
Ambulatory Care Reporting System; BMI: Body mass index; AS: Antenatal specialty; PSFU: Prenatal screening follow-up; WHO: World Health Organization; OR: Odds ratio; OHIP: Ontario Health Insurance Plan; GA: Gestational age

\section{Acknowledgements}

We thank all BORN staff, especially Dr. Lise Bisnaire, Ms. Shelley Dougan, Mr. Ian Joiner, Ms. Merryn Douglas, and Ms. Shelley Kennedy for their great 
support of this project; Ms. Catherine Riddell and Cathy Yang for their excellent comments for SAS code and analysis results review. We also thank $\mathrm{CIHI}$ for providing the $\mathrm{CIHI}-\mathrm{DAD}$ data to BORN.

\section{Authors' contributions}

$\mathrm{QM}$ : project development, data management and analysis, manuscript writing and editing. SD, SW, JL, and MK: project development, and manuscript review and revision. JR and CLV: manuscript review and revision. All authors read and approved the final manuscript.

\section{Funding}

This study is funded by a Canadian Institutes of Health Research (CIHR) Early Career Investigator Award in Maternal, Reproductive, Child and Youth Health (CIHR Institute of Circulatory and Respiratory Health) in Canada. The funding partner is BORN Ontario. The funders had no role in the design of the study and collection, analysis, and interpretation of data and in writing the manuscript

\section{Availability of data and materials}

The data analyzed during this study is held securely at the prescribed registry BORN Ontario. Data sharing regulations prevent this data from being made available publicly due to the personal health information in the datasets. Enquiries regarding BORN data must be directed to BORN Ontario (Science@BORNOntario.ca).

\section{Ethics approval and consent to participate}

This study has been approved by the Research Ethics Board boards from the Children's Hospital of Eastern Ontario and the Ottawa Health Science Network Research. This study was deemed exempt from obtaining consent by the Research Ethics Boards.

\section{Consent for publication}

Not applicable.

\section{Competing interests}

The authors declare that they have no competing interests.

\section{Author details}

'BORN Ontario, Ottawa, Ontario, Canada. ${ }^{2}$ Children's Hospital of Eastern Ontario Research Institute, Ottawa, Ontario, Canada. ${ }^{3}$ School of Epidemiology and Public Health, University of Ottawa Faculty of Medicine, Ottawa, Canada. ${ }^{4}$ OMNI Research Group, Clinical Epidemiology Program, Ottawa Hospital Research Institute, Ottawa, Canada. ${ }^{5}$ School of Nursing, University of Ottawa, Ottawa, Ontario, Canada. ${ }^{6}$ Department of Obstetrics \& Gynecology, University of Ottawa Faculty of Medicine, Ottawa, Canada. ${ }^{7}$ Department of Pediatrics, Children's Hospital of Eastern Ontario, Ottawa, Ontario, Canada. ${ }^{8}$ Department of Pediatrics, University of Ottawa, Ottawa, Ontario, Canada.

\section{Received: 15 September 2020 Accepted: 21 December 2020}

\section{Published online: 21 January 2021}

\section{References}

1. Hoffman JIE. The global burden of congenital heart disease. Cardiovasc J Afr. 2013;24(4):141-5.

2. Kochanek KD, Murphy SL, Xu J, Tejada-Vera B. National vital statistics reports Deaths: final data for 2014. 2016; 65(4). [cited 2020 Jul 21]. Available from: https://www.cdc.gov/nchs/data/nvsr/nvsr65/nvsr65_04.pdf.

3. Sayasathid J, Sukonpan K, Somboo N. Epidemiology and etiology of congenital heart diseases. In: Syamasundar Rao P, editor. Congenital heart disease - selected aspects: InTech; 2012. p. 47-84.

4. Irvine B, Luo W, León JA. Perinatal health indicators 2013: a surveillance report by the Public Health Agency of Canada's perinatal surveillance system. Heal Promot Chronic Dis Prev Can. 2015;35(1):23-4.

5. Mulder BJM. Epidemiology of adult congenital heart disease: demographic variations worldwide. Neth Hear J. 2012;20(12):505-8.

6. Quan H, Li B, Duncan Saunders L, Parsons GA, Nilsson Cl, Alibhai A, et al. Assessing validity of ICD-9-CM and ICD-10 administrative data in recording clinical conditions in a unique dually coded database. Health Serv Res. 2008; 43(4):1424-41.

7. Congenital heart disease in elementary school children in rural Thailand: the role of the trained noncardiologist. https://doi.org/10.5372/1905-7415.0702 178 .
8. Parnell AS, Correa A. Analyses of trends in prevalence of congenital heart defects and folic acid supplementation. J Thorac Dis. 2017;9(3):495-500.

9. Liu S, Joseph KS, Luo W, León JA, Lisonkova S, Van den Hof M, et al. Effect of Folic Acid Food Fortification inCanada on Congenital Heart Disease Subtypes. Circulation. 2016;134(9):647-55. https://doi.org/10.1161/ CIRCULATIONAHA.116.022126.

10. Botto LD, Correa A. Decreasing the burden of congenital heart anomalies: an epidemiologic evaluation of risk factors and survival. Prog Pediatr Cardiol. 2003;18:111-21. ISSN 1058-9813.

11. Vrijheid M, Dolk H, Stone D, Abramsky L, Alberman E, Scott JES. Socioeconomic inequalities in risk of congenital anomaly. Arch Dis Child. 2000;82(5):349-52

12. Yu D, Feng $Y$, Yang L, Da M, Fan C, Wang S, et al. Maternal socioeconomic status and the risk of congenital heart defects in offspring: a meta-analysis of 33 studies. PLoS One. 2014:9(10):e111056.

13. Deguen S, Kihal W, Jeanjean M, Padilla C, Zmirou-Navier D. Neighborhood deprivation and risk of congenital heart defects, neural tube defects and orofacial clefts: a systematic review and meta-analysis. PLoS One. 2016; 11(10):e0159039.

14. Agha MM, Glazier RH, Moineddin R, Moore AM, Guttmann A. Socioeconomic status and prevalence of congenital heart defects: does universal access to health care system eliminate the gap? Birth Defects Res Part A - Clin Mol Teratol. 2011;91(12):1011-8.

15. Wen SW, Miao Q, Taljaard M, Lougheed J, Gaudet L, Davies M, et al. Associations of assisted reproductive technology and twin pregnancy with risk of congenital heart defects. JAMA Pediatr. 2020;174(5):446-54.

16. Cai $L$, Zhu Y. The challenges of data quality and data quality assessment in the big data era. Data Sci J. 2015;14(0):2.

17. Wang C, Guttmann A, To T, Dick PT. Neighborhood income and health outcomes in infants: how do those with complex chronic conditions fare? Arch Pediatr Adolesc Med. 2009;163(7):608-15

18. Abu-Saad K, Fraser D. Maternal nutrition and birth outcomes. Epidemiol Rev. 2010;32(1):5-25

19. Pampel FC, Krueger PM, Denney JT. Socioeconomic disparities in health behaviors. Annu Rev Sociol. 2010;36(1):349-70.

20. Carmichael SL, Shaw GM, Yang W, Abrams B, Lammer EJ. Maternal stressful life events and risks of birth defects. Epidemiology. 2007;18(3):356-61.

21. Carmichael SL, Ma C, Tinker S, Rasmussen SA, Shaw GM. Maternal stressors and social support as risks for delivering babies with structural birth defects. Paediatr Perinat Epidemiol. 2014;28(4):338-44.

22. Chan E, Serrano J, Chen L, Stieb DM, Jerrett M, Osornio-Vargas A. Development of a Canadian socioeconomic status index for the study of health outcomes related to environmental pollution. BMC Public Health. 2015;15(1):714

23. Shimmin C, Millar J. Why economic inequality matters to the health and well-being of all Canadians. http://evidencenetwork.ca/why-economicinequality-matters-to-the-health-and-well-being-of-all-canadians/. Accessed 2 Jan 2021.

24. Statistics Canada. Census in Brief. Children living in low-income households2016 Canadian Census [Internet]. [cited 2020 Dec 15]. Available from: https://www12.statcan.gc.ca/census-recensement/2016/as-sa/98-200x/2016012/98-200-x2016012-eng.cfm.

25. Larson CP. Poverty during pregnancy: its effects on child health outcomes. Paediatr Child Health. 2007;12(8):673

26. Statistics Canada. 2016 census of population. https://www12.statcan.gc ca/census-recensement/2016/dp-pd/index-eng.cfm (2016). Accessed 22 July 2020.

27. Galobardes B, Shaw M, Lawlor DA, Lynch JW, Smith GD. Indicators of socioeconomic position (part 1). J Epidemiol Community Health. 2006:60:7-12.

28. Miao Q, Fell DB, Dunn S, Sprague AE. Agreement assessment of key maternal and newborn data elements between birth registry and clinical administrative hospital databases in Ontario, Canada. Arch Gynecol Obstet. 2019;300(1):135-43.

29. Dunn S, Lanes A, Sprague AE, Fell DB, Weiss D, Reszel J, et al. Data accuracy in the Ontario birth registry: a chart re-abstraction study. BMC Health Serv Res. 2019:19(1):1-11.

30. Dunn S, Sprague AE, Grimshaw JM, Graham ID, Taljaard M, Fell D, et al. A mixed methods evaluation of the maternal-newborn dashboard in Ontario: dashboard attributes, contextual factors, and facilitators and barriers to use: a study protocol. Implement Sci. 2016:11(1):1-11. https://doi.org/10.1186/ s13012-016-0427-1. 
31. Sprague AE, Sidney D, Darling EK, Wagner V, Soderstrom B, Rogers J, et al. Outcomes for the first year of Ontario's birth center demonstration project. J Midwifery Womens Health. 2018;63(5):532-40. https://doi.org/10.1111/ jmwh.12884.

32. eDAD and eNACRS Reports User Guide [Internet]. Canadian Institute for Health Information (CIHI). [cited 2018 May 10]. Available from: https://www. cihi.ca/en/enacrs_user_guide_en.pdf.

33. Canadian Insititute for Health Information (CIHI). Discharge abstract database metadata (DAD) [Internet]. Canada, 2020 [updated 2020; cited 2020 July 29]. Available from: https://www.cihi.ca/en/discharge-abstractdatabase-metadata-dad.

34. Statistics Canada. Postal code conversion file plus (PCCF+) version 7B [Internet]. 2017 [cited 2020 Dec 15]. Available from: https://www150.statcan. gc.ca/n1/en/catalogue/82F0086X.

35. Statistics Canada. 2016 Canadian census [Internet]. [cited 2020 Dec 15]. Available from: https://www12.statcan.gc.ca/census-recensement/2016/dppd/index-eng.cfm.

36. Miao Q, Chen D, Buzzelli M, Aronson KJ. Environmental equity research: review with focus on outdoor air pollution research methods and analytic tools. Arch Environ Occup Health. 2015;70(1):47-55.

37. Blakely $T$, Hales $S$, Woodwark A. Poverty: assessing the distribution of health risks by socioeconomic position at national and local levels. Geneva: World Health Organization; 2004. Available from: https://www.who.int/quantifying_ ehimpacts/publications/en.

38. SAS Institute Inc. Base SAS 9.4 procedures guide. Cary: SAS Institute Inc:; 2011.

39. De Jong GF, Madamba AB. A double disadvantage? Minority Group, immigrant status, and underemployment in the United States. Soc Sci Q. 2001;82(1):117-30. https://doi.org/10.1111/0038-4941.00011.

40. Wanigaratne S, Shakya Y, Gagnon AJ, Cole DC, Rashid M, Blake J, et al. Refugee maternal and perinatal health in Ontario, Canada: a retrospective population-based study. BMJ Open. 2018;8(4):1-11.

41. Vang ZM, Sigouin J, Flenon A, Gagnon A. Are immigrants healthier than native-born Canadians? A systematic review of the healthy immigrant effect in Canada. Ethn Health. 2017;22(3):209-41. https://doi.org/10.1080/13557858. 2016.1246518.

42. Riosmena F, Kuhn R, Jochem WC. Explaining the immigrant health advantage: self-selection and protection in health-related factors among five major national-origin immigrant groups in the United States. Demography. 2017:54:175-200.

43. Canadian Multiculturalism [Internet]. [cited 2020 Aug 4]. Available from: https://lop.parl.ca/sites/PublicWebsite/default/en_CA/ ResearchPublications/200920E.

44. Darin-Mattsson A, Fors S, Kåreholt I. Different indicators of socioeconomic status and their relative importance as determinants of health in old age. Int J Equity Health. 2017;16(1):1-11.

45. Kučienè R, Dulskienè V, Kučienè R. Maternal socioeconomic and lifestyle factors during pregnancy and the risk of congenital heart defects correspondence to. Medicina. 2009:45:904-9.

46. Ou Y, Mai J, Zhuang J, Liu X, Wu Y, Gao X, et al. Risk factors of different congenital heart defects in Guangdong, China. Pediatr Res. 2016;79:549-58.

\section{Publisher's Note}

Springer Nature remains neutral with regard to jurisdictional claims in published maps and institutional affiliations.

\section{Ready to submit your research? Choose BMC and benefit from:}

- fast, convenient online submission

- thorough peer review by experienced researchers in your field

- rapid publication on acceptance

- support for research data, including large and complex data types

- gold Open Access which fosters wider collaboration and increased citations

- maximum visibility for your research: over $100 \mathrm{M}$ website views per year

At $\mathrm{BMC}$, research is always in progress.

Learn more biomedcentral.com/submissions 